Pontifícia Universidade Católica do Rio de Janeiro

Restaurantes em formato Dark Kitchen: inovação smart para uma era informatizada

João Victor Medawar Machado

TRABALHO DE CONCLUSÃO DE CURSO

Centro de Ciências Sociais - CCS Departamento de Administração Graduação em Administração de Empresas 


\section{Restaurantes em formato Dark Kitchen: inovação smart para uma era informatizada}

Trabalho de Conclusão de Curso

Trabalho de Conclusão de Curso, apresentado ao programa de graduação em Administração da PUC-Rio como requisito parcial para a obtenção do título de graduação em Administração.

Orientadora: Prof. Luiza Martins

Rio de Janeiro Junho de 2021 
"O futuro pertence àqueles que acreditam na beleza dos seus sonhos" Eleanor Roosevelt (1884-1962) 


\section{AGRADECIMENTOS}

Tive muitas inspirações durante o período acadêmico que contribuíram para realização deste trabalho, desde professores a estudantes que me inspiraram com seu trabalho e conhecimento.

Gostaria de expressar a minha felicidade e sentimento de superação por concluir mais uma meta na minha vida.

Agradeço também a minha família que me apoiou e serviu de exemplo para conclusão desta graduação.

Aos amigos que me ajudaram dando apoio moral, compartilhando experiências, diversão e alegrias.

À minha orientadora, Luiza Martins, que se disponibilizou a me ajudar a compor este trabalho.

Por fim, agradeço a esta instituição de ensino por pavimentar o caminho para meu crescimento e me fazer tantas conexões importantes que enriqueceram a minha experiência. 


\section{RESUMO}

Machado, João Victor Medawar. Restaurantes em formato Dark Kitchen: inovação smart para uma era informatizada. Rio de Janeiro, 2021. 43p. Trabalho de Conclusão de Curso Departamento de Administração. Pontifícia Universidade Católica do Rio de Janeiro.

A forte expansão do e-commerce, através da compra e venda no mundo virtual, fez com que aplicativos de smartphones experimentassem um notável aumento na demanda de downloads. As empresas, que buscaram se adequar a nova forma de consumo, estariam preparadas para o infortúnio que ameaçou a economia, o comércio e indústrias mundialmente: a pandemia provocada pelo coronavírus (Covid-19). Dentro desse contexto, a dark kitchen surge como uma solução smart para superar as barreiras enfrentadas pela sociedade. Salienta-se que, antes mesmo da pandemia, esse modelo de cozinha já era empreendido com o objetivo de realizar entregas em áreas urbanas e industriais na Europa. O foco das cozinhas fantasmas é a entrega da refeição solicitada por meio virtual, deixando de lado os gastos com mobiliário, estrutura de salão, aluguéis caríssimos em locais estratégicos - e, ainda, facilita a gestão de pessoas. Diante de tais mudanças, o trabalho analisará empresas que têm empreendido no modelo dark kitchen, além disso, serão apresentadas as estatísticas do consumo de refeições via aplicativo; os conceitos de smart city e e-commerce; formação e redução dos custos, bem como o perfil do consumidor de delivery.

\section{Palavras-chave}

Dark kitchen; e-commerce; smart city; perfil do consumidor; 


\section{ABSTRACT}

Machado, João Victor Medawar. Dark Kitchen format restaurants: smart innovation for a computer age. Rio de Janeiro, 2021, 43p. Course Conclusion Paper - Administration Department. Pontifical Catholic University of Rio de Janeiro.

The strong expansion of e-commerce, through buying and selling in the virtual world, has made smartphone apps experience a notable increase in the demand for downloads. Companies, which sought to adapt to the new form of consumption, would be prepared for misfortune that threatened the economy, trade and industries worldwide: the pandemic caused by the Corona Virus Disease (Covid-19). Within this context, the dark kitchen has emerged as a smart solution to overcome the barriers faced by society. It should be noted that, even before the pandemic, this kitchen model was already being undertaken with the aim of making deliveries in urban and industrial areas in Europe. The focus of the ghost kitchens is the meal delivered through a virtual medium, leaving aside the expenses with furniture, lounge structure, very expensive rentals in strategic locations - and it also facilitates the management of people. Before these changes, the work will analyze companies that have undertaken in the dark kitchen model, in addition, it will present the statistics of the consumption of meals via the application; the Smart City and e-commerce concepts, training and cost reduction, as well as the delivery consumer profile.

\section{Keywords}

Dark kitchen; e-commerce; smart city; consumer profile; 


\section{LISTA DE TABELAS}

Tabela 1 - Custos indiretos de entregas a domicílio

28

Tabela 2 - Vantagens e desvantagens da dark kitchen 


\section{LISTA DE ILUSTRAÇÕES}

Gráfico 1 - Pesquisa Nacional por amostra domicílios contínua

Gráfico 2 - Uso dos aplicativos de delivery no interior do Brasil 


\section{SUMÁRIO}

1. Introdução 10

1.2. Objetivos 11

1.2.1. Objetivo principal 11

1.2.2 Objetivos secundários $\quad 12$

1.3. Delimitação do estudo 12

1.4. Relevância do estudo 12

2. Referencial Teórico 14

2.1. Breve esboço histórico sobre a formação dos restaurantes e sua função social 14

2.2 Transformações no consumo de refeições provocadas pelo surgimento da internet 14

2.2.1 As plataformas digitais de compra e venda no ramo alimentício 17

2.2.2. Vantagens e desvantagens advindas do comércio digital 19

2.3 O Perfil do Consumidor de delivery 21

2.3.1 O Impacto econômico do delivery 22

2.3.2 Impacto social do delivery 23

2.4. O Conceito de Smart City e as implicações para a implementação de cidades inteligentes

2.4.1 Dark Kitchen como uma inovação smart 25

2.4.2 Dark Kitchen: Redução nos custos e formação de preços de venda 27

3. Metodologia 30

3.1. Tipo de pesquisa $\quad 30$

3.2. Coleta de dados 30

4. Análise dos dados 33

4.1. Comparação entre os estabelecimentos 33

4.2. Vantagens e desvantagens do delivery 34

4.3. Importância dessa análise para a execução do trabalho 35

4.4 Limitações ao método e projetos futuros 36

5. Considerações Finais 37

Referências Bibliográficas

ANEXOS $\quad 43$ 


\section{Introdução}

Dark Kitchen ou Ghost Kitchen é um conceito relacionado a uma nova modalidade de restaurante que oferece apenas serviço de produção e entrega de comida, isto é, delivery ou drive-thru. Em outras palavras, neste tipo de empresa não há refeitório; é um negócio estritamente para entrega, com aparato de uma cozinha industrial, que fornece os pedidos solicitados através de marketplaces em aplicativos de dispositivos móveis ou por meio de contato via telefone. Este novo formato de negócio foi aperfeiçoado no ano de 2016 pela empresa Deliveroo, especialista no serviço de entrega de alimentos a domicílios.

As cozinhas fantasmas eram empreendidas nos estacionamentos ou em áreas amplas no complexo industrial de Londres, local onde havia uma forte demanda de delivery. A jornalista britânica Rebecca Wearn (2019), em reportagem para a BBC News (2019) ${ }^{1}$, afirma que a indústria do "take away" atingiu o valor de 4,9 bilhões de libras esterlinas até meados de 2019, conforme levantamento de consumo do NPD Group.

O presente trabalho, analisará o desenvolvimento das cozinhas fantasmas e como essa tendência de restaurantes digitais vem se sobrepondo aos modelos tradicionais de restaurantes, principalmente, diante das ameaças externas que permeiam o mundo globalizado.

No final de 2019 e início de 2020, a pandemia do novo coronavírus (COVID-19) impôs enormes mudanças no cotidiano da população urbana, impactando também os negócios. Neste novo cenário, alguns temas começam a ser mais abordados de forma recorrente, como a entrada da tecnologia como uma solução, como na pesquisa de Denise Vogel, diretora de Planejamento e Projetos Urbanos do Instituto Niemeyer, intitulado "Das proto-cidades às smart cities: reflexão a partir do coronavírus" Vogel (2020) apresenta as soluções tecnológicas que vêm recebendo investimentos governamentais em países emergentes para manter o desenvolvimento econômico e as novas demandas da classe média nas áreas metropolitanas.

A autora cita, ainda, que o conceito de smart city se inicia entre 2016 e 2017 na Alemanha e se estende a outros países no continente europeu, asiático e norte-americano, traduzindo-se num plano de organização social no qual "tecnologias como big data e inteligência artificial são usadas para criar soluções com foco nas necessidades humanas." (VOGEL, 2020, p. 66). 
Para a autora, as smart cities devem possuir uma integração no uso dos espaços físicos e cibernéticos. Ela salienta ainda que é um grande desafio para as cidades brasileiras atingirem boas posições no ranking internacional que revela o grau de inteligência nas maiores cidades do mundo, principalmente considerando a falta de infraestrutura, coesão social, capital humano e governança locais.

Considerando o Decreto $n^{\circ} 47.285$ de 23 de março de 2020, que complementa as restrições para enfrentamento da pandemia no novo coronavírus na cidade do Rio de Janeiro e o Decreto $n^{\circ} 46.973$, publicado no dia 16 de março de 2020 , que estabeleceu restrições e medidas de enfrentamento da propagação da doença (RIO DE JANEIRO, 2020), as tecnologias passaram a ser grande aliadas das empresas que, agora, precisavam de alternativas digitais para continuarem entregando seus produtos e serviços para seus clientes.

Para David Rogers (2017):

A transformação digital não tem a ver com tecnologia - tem a ver com estratégia e novas maneiras de pensar. Transformar-se para a era digital exige que o negócio atualize sua mentalidade estratégica, muito mais que sua infraestrutura de TI (ROGERS, p. 10, 2017).

Será analisado também no referencial teórico o professor João Yanase (2018), o qual traz abordagens sobre a apuração dos custos e o preço de venda; tema de extrema importância para os gestores que administram o negócio de acordo com a receita e os custos.

Definitivamente, a dinâmica smart será cada vez mais apreciada pelos governos estatais que apontam as consequências da austeridade como uma motivação para implementar uma transformação digital na promessa de incentivar a criatividade e o empreendedorismo dentre os cidadãos. E é a partir desta perspectiva da necessidade de transformação digital smart que este trabalho será desenvolvido.

\subsection{Objetivos}

\subsubsection{Objetivo principal}

Como objetivo principal, será analisado o desenvolvimento das dark kitchens no Brasil como um modelo de negócio promissor. Será abordado como esta proposta de negócio tem encontrado apoio na concepção de smart city, analisando-se o custo-benefício e quais barreiras podem ser encontradas durante o empreendimento. 


\subsubsection{Objetivos secundários}

De modo a alcançar o objetivo final do estudo, é necessário pesquisar e analisar todo o contexto e particularidades em que se insere o tema. Com isto, podemos ressaltar alguns objetivos intermediários como: entender como se deu início esse novo modelo de cozinha; analisar os benefícios da nova modalidade, principalmente diante de cenários como o da pandemia provocada pelo COVID-19.

\subsection{Delimitação do estudo}

Este estudo está delimitado a identificar os aspectos positivos e negativos trazidos pela introdução das cozinhas fantasma. Abrangerá as novas formas de negócios advindas da difusão de novas tecnologias digitais e, com isso, obriga-nos a aprofundar o reexame do caminho do consumidor para a compra. Para isso, é importante analisar o novo comportamento desse consumidor que interage, constrói e avalia a reputação das empresas e das marcas. A infraestrutura da cidade carioca também será investigada dentro do conceito de Smart City. Ao empreendedor, cabe a inovação que as tecnologias digitais possibilitam, trazendo um aprendizado duradouro, por experimentação rápida. Atualmente, é possível captar reações positivas e negativas do mercado de consumo desde o início da ideia, analisando-as até o lançamento, e mesmo depois.

\subsection{Relevância do estudo}

Essa nova abordagem de cozinha fantasma está alinhada ao entendimento de "cidade inteligente" e ao novo contexto de distanciamento social - e o que foi antes, dificilmente será o que é hoje ou será amanhã. Portanto, faz-se necessário estudar a viabilidade do negócio que cresce na era digital. Para isso, é importante averiguar a qualidade da rede de clientes, a competição de mercado, os dados de como as empresas gerenciam, produzem e usam a informação e a inovação.

O conceito "smart" traz à tona a ideia de realizar e desempenhar algo de forma mais inteligente. Pensar "smart" requer ter ideias "fora da caixa" e que mudam o conceito de concorrência. Em outras palavras, as empresas precisam rever valores e a forma como se apresentam no mercado, sob o risco de serem engolidas por outros concorrentes até então inexistentes, como o caso das "dark kitchen".

Segundo Telles (2018), é possível planejar o futuro dentro do padrão "smart". O autor cita como exemplo o Airbnb que mudou o mercado da indústria hoteleira, tendo em vista que pessoas físicas agora podem disponibilizar os espaços de suas casas para hospedar 
viajantes. Do mesmo modo, as "dark kitchen" alcançam bons resultados, inclusive em situações adversas, como a pandemia que estamos atravessando, em que ter um espaço para refeição pode não ser mais tão vantajoso quanto antes já foi.

Historicamente, o consumidor buscava se alimentar em um restaurante para ter uma experiência composta tanto pelo serviço prestado no local, quanto pela comida oferecida, muitas vezes em uma qualidade que dificilmente se obtém na cozinha de casa. Hoje as dark kitchen procuram trazer o máximo desta experiência no seu serviço de delivery, visando oferecer não só uma culinária de alta qualidade, mas também um serviço que enriquece a experiência do cliente, criando valor adicional, mas na própria casa do consumidor.

Sendo assim, a inovação a partir do modelo das dark kitchen na indústria alimentícia se torna um objeto de estudo relevante para o atual momento pandêmico e de estabilização da economia tanto do Estado quanto dos cidadãos que procuram se reinventar através do empreendedorismo. 


\section{Referencial Teórico}

\subsection{Breve esboço histórico sobre a formação dos restaurantes e sua função social}

Desde a pré-história os homens estabeleceram uma forte relação com o alimento, seja para dividir a caça ou para adorar deuses nas primeiras civilizações da mesopotâmia. Atualmente, o hábito de alimentar adquire um novo sentido diante das circunstâncias sociais, econômicas e dos meios de produção. Antes, a mulher casada era responsável pelo preparo das refeições em família, hoje, ela, que também trabalha fora, prefere ter mais tempo para se dedicar à família e descansando em casa do que passar muitas horas na frente de um fogão cozinhando.

A invenção e chegada do hambúrguer no início do século $X X$ também foi essencial para a disseminação da comida rápida, feita em minutos ou até mesmo em segundos. $O$ fastfood foi, assim, a introdução do taylorismo, isto é, da divisão do trabalho à preparação de refeições servidas em restaurantes, o que provocou um fenômeno de produção em série, homogênea e padronizada.

\subsection{Transformações no consumo de refeições provocadas pelo surgimento da internet}

Compreender o desenvolvimento do comércio eletrônico é primordial para a análise do presente trabalho. O surgimento de novas tecnologias abre um leque de inovação empresarial. Há, atualmente, diversos meios para iniciar um negócio online para compra e venda, dentre outras atividades. O mundo, naturalmente, vem passando por um processo de transformação.

No início da Revolução Industrial, que se deu na Inglaterra, as fábricas dependiam de fontes fixas de energia, como as rodas d'água, localizadas próximas aos rios e, posteriormente, precisou-se da energia a vapor que era oriunda de máquinas que queimavam carvão. Cumpre ressaltar que, no século XIX, a energia elétrica era tão inovadora quanto a internet é hoje. Segundo Rogers (2017) as fábricas antigas também demoraram para se 
adaptar à nova tecnologia. Sendo assim, coube às novas empresas geradoras de energia elétrica trazer as "startups" da era elétrica para inovar na manufatura.

A partir de 1920 já havia um novo modelo de indústria, produtos e negócios que giravam em torno da energia elétrica. Hoje, pode-se dizer que empresas como Google e Amazon são as nativas digitais que são como as geradoras de energia elétrica no início da era da eletrificação.

As transformações que ocorrem na sociedade também são frutos das necessidades, valores e interesses coletivos. As funções e os processos dominantes na era da informação estão cada vez mais organizados em termo de redes. Embora a forma de organização social em redes tenha existido em outros tempos, o novo paradigma da tecnologia da informação fornece a base material para sua expansão penetrante em toda a estrutura social.

O surgimento da internet foi o principal motivo por trás da expansão do ecommerce (comércio eletrônico). O comércio online é definido por Carvalho (2014) como uma transação que ocorre, exclusivamente, através de ferramentas digitais, podendo ser smartphones, tablets, notebook ou computadores, desde que estejam conectados à internet.

O autor Alberto Albertin (2000) se refere ao e-commerce como:

(...) A realização de toda a cadeia de valor dos processos de negócios num ambiente eletrônico, por meio da aplicação intensa das tecnologias de comunicação e de informação, atendendo aos objetivos do negócio. Os processos podem ser realizados de forma completa ou parcial, numa infraestrutura predominantemente pública, de fácil Acesso e a baixo custo como a Internet. (ALBERTIN, 2002, p.64)

Nesse sentido, o comércio eletrônico envolve um conjunto de empresas, produtos e pessoas, ainda mais por ser um meio prático e moderno, onde se pode praticar as atividades de compra e venda em qualquer lugar do mundo, com preço e custos reduzidos e que reúne rapidez e eficiência. Esta forma de comércio tem mudado a maneira das pessoas e empresas encararem a atividade comercial e vem crescendo, principalmente, pelo uso popular da internet. A popularização da internet e o uso dela em dispositivos móveis, como o smartphone, possibilitou um maior número de usuários desde as classes mais ricas até as menos abastadas. Pode-se citar a afirmação de Thiago Mithidieri (2015):

O comportamento dos internautas mudou bastante nas duas últimas décadas. No início, a Internet era utilizada praticamente por universitários e, posteriormente, apenas as classes A e B compravam pela rede mundial de computadores [...] a participação da classe $C$ ficou muito maior, e hoje quase metade das compras online é efetuada por esse público, fazendo com que a evolução do e-commerce esteja intimamente ligada à popularização da Internet no Brasil. (MITHIDIERI, 2015, p.24) 
De acordo com uma pesquisa realizada pelo IBGE $^{1}$ em 2019, a internet era utilizada em $82,7 \%$ dos lares brasileiros, com a maior parte desses domicílios situada nas grandes regiões urbanas:

Gráfico 1: Pesquisa Nacional por amostra domicílios contínua.

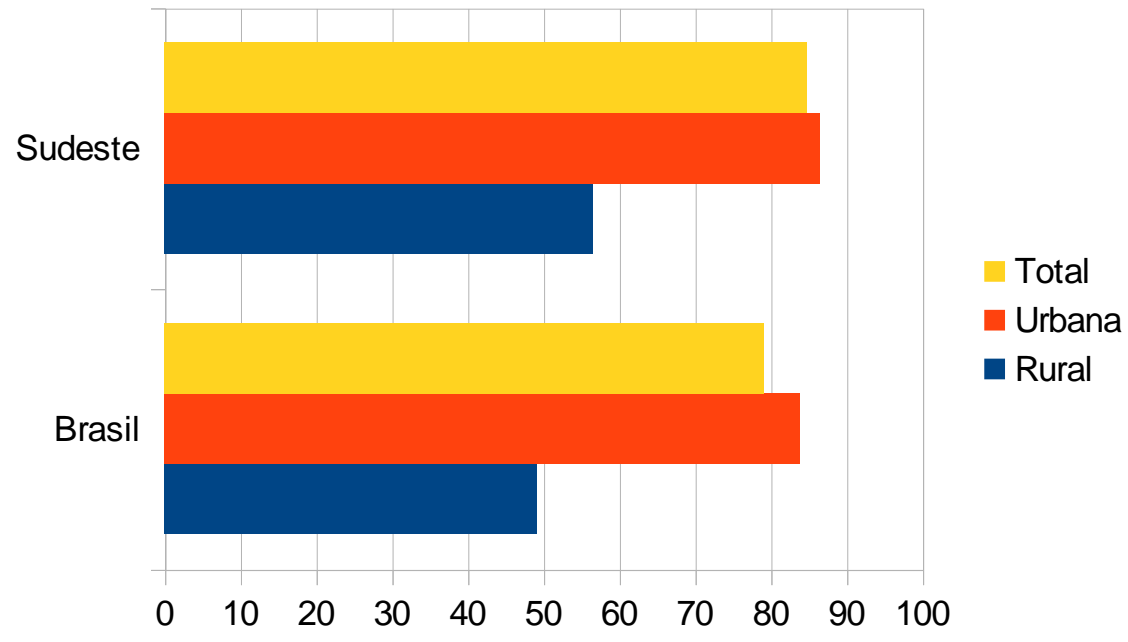

Fonte: IBGE, Diretoria de Pesquisas. Pesquisa Nacional por Amostra Domicílios Contínua 2019

Com o enorme aumento de usuários da Internet, ao longo desses anos cresceu também o comércio eletrônico no país. Desta forma, surgiram os grandes sites ou aplicativos de e-commerce e marketplace, como Mercado Livre, Americanas.com, OLX e Airbnb. As inovações tecnológicas que ocorrem ano após ano têm a faculdade de otimizar o comércio online com mecanismos de vendas cada vez mais adequados aos diversos perfis de consumidores existentes.

Assim, o e-commerce representa o futuro do comércio, visto que existem milhares de oportunidades de negócios através das plataformas digitais que oferecem serviços como o melhor preço, o melhor produto ou a melhor avaliação do consumidor. Apesar de haver uma parcela da população que ainda vive o "analfabetismo digital", por outro lado, há uma significativa quantidade de jovens que já nasceram no alvorecer tecnológico e que promovem uma grande movimentação econômica.

As tecnologias digitais, inevitavelmente, mudaram também a maneira em que empresas encaram a competição. Salienta-se que a competição não é apenas com empresas rivais do próprio setor de atividade, mas também com negócios de outros ramos. Os recursos competitivos, por sua vez, não se concentram mais numa organização, mas sim numa rede

${ }^{1}$ IBGE. Instituto Brasileiro de Geografia e Estatística. Uso de Internet, televisão e celular no Brasil. 2019. Disponível em: https://educa.ibge.gov.br/jovens/materias-especiais/20787-uso-de-internettelevisao-e-celular-no-brasil.html. Acesso em: 13 nov. 2020. 
de parceiros em relações de negócios. Nos negócios tradicionais os dados eram difíceis de se obter e armazenar.

O gerenciamento de tais dados requisitava a compra, manutenção e investimento na parte tecnológica do negócio. No mundo moderno, os dados são gerados de forma avassaladora, a toda hora e em todos os lugares. Além disso, os padrões de facilidade, velocidade e onipresença se alteram rapidamente. Enquanto em outros tempos, uma compra pela internet poderia levar dias para chegar ao destinatário, hoje, há rastreamento do pedido e a inovação nas formas de logística e distribuição permitem uma entrega cada vez mais rápida e segura.

Contudo, isso não significa que o comércio online seja a única opção, os modelos tradicionais com local físico ainda existem e são relevantes para a economia. O que determinará, serão as expectativas do consumidor levando-se em conta alguns questionamentos e o contexto em que está inserido. Essa análise será explanada mais adiante a partir da análise do perfil do consumidor.

\subsubsection{As plataformas digitais de compra e venda no ramo alimentício}

O mercado digital é uma área em expansão no Brasil. Nos últimos anos houve um aumento considerável das plataformas digitais que ajudaram a multiplicar os empreendedores virtuais. Observa-se uma grande variedade de aplicativos de compra e venda no ramo alimentício como o Rappi, Ifood, Uber eats, entre outras gigantes.

A jornalista britânica Rebecca Wearn (2019), em reportagem para a BBC News², afirma que a indústria do "take away" atingiu o valor de 4,9 bilhões de libras esterlinas até meados de 2019, conforme levantamento de consumo do NPD Group.

Diante da expansão do serviço de entregas de refeições, a empresa Delivery Much, em 2021, realizou uma pesquisa sobre como é a utilização dos aplicativos de delivery no interior do Brasil:

Gráfico 2: uso dos aplicativos de delivery no interior do Brasil.

2WEARN, Rebecca (ed.). Does your dinner come from a 'dark kitchen'? 2019. Disponível em: https://www.bbc.com/news/business-47978759. Acesso em: 10 out. 2020. 


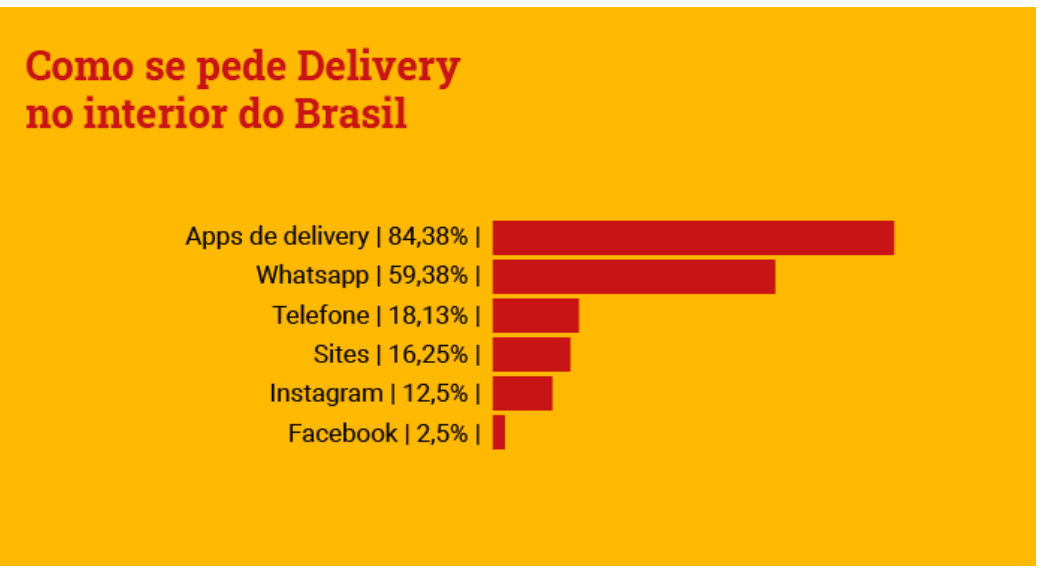

Fonte: Delivery Much. 2021.

O autor Arthur Igreja (2019) ressalta o boom das plataformas digitais de compra e venda como um atrativo de novos negócios e empresários que, por ter pouco tempo atuando na área, talvez não teriam tanta credibilidade no sistema de compras online. A título de exemplificação, ele aborda que:

\begin{abstract}
Quando você compra no site, muitas vezes o produto é apenas processado pela Amazon; caso aquele pequeno comerciante tivesse tentado colocar no ar seu próprio e-commerce, teria grande dificuldade em atrair tráfego para o site, além de ter que arcar com todo o investimento para operar a plataforma. Mas, acima de tudo, o fator mais importante é a confiança no processo como um todo. Poucos comprariam do site da mercearia da esquina. No entanto, quando ela faz parte de uma plataforma que padroniza e garante a jornada de compra, vemos a conexão destas 3 partes: fornecedor, entregador e consumidor. (IGREJA,2020, p. 83)
\end{abstract}

Segundo Rogers (2017), ainda há organizações que permanecem atreladas a processos mais tradicionais, unidirecionais e hierarquizados no que se refere ao relacionamento, à comunicação e à estruturação de suas atividades. Nesse contexto, é válido lembrar que nada é tão fácil quanto parece, pois ainda há importantes desafios a superar no ramo tecnológico, como o analfabetismo digital, as desigualdades sociais, a falta de infraestrutura em algumas regiões, a falta de acesso à internet, entre outros aspectos.

Aponta, ainda, que atualmente a internet e o uso de aplicativos representam uma estratégia de acesso simplificada, com conveniência e flexibilidade. Assim, há uma gama de serviços que ajudam a empresa a criar valor adicional para os clientes, bem como conquistar a lealdade deles.

A Receita Federal também apontou que em 2019 havia mais de 200 mil microempreendedores individuais atuando no fornecimento de refeições, isto é, atividade 
econômica focada em delivery. Segundo dados recolhidos pelo Sebrae, o crescimento da atividade foi de $122 \%$ em cinco anos. ${ }^{3}$

Em 2018 o número de restaurantes cadastrados no iFood era 50 mil, já em 2019, o número dobrou para 100 mil. No ano de 2020, especialmente pela pandemia, o iFood possuía cerca de 160 mil restaurantes registrados. ${ }^{4}$

Inegavelmente, fomentou-se a ideia de que o smartphone e a internet são capazes de solucionar todos os entraves do cotidiano. O uso do celular, atualmente, ultrapassa e muito o significado de apenas se comunicar - ele serve para pagar um boleto bancário, solicitar a refeição, reservar um hotel ou passagens aéreas e para se locomover, bastando chamar um carro privado através de um aplicativo.

\subsubsection{Vantagens e desvantagens advindas do comércio digital}

Para utilizar a internet como um recurso para vendas, compras e trocas, é importante analisar as vantagens e desvantagens da ferramenta. Pode-se citar como vantagem o acesso direto do consumidor ao produto, podendo, ainda, mostrar a criação, transformação e a inovação da coisa, com o intuito de fidelizar o cliente. (FERREIRA e PITWAK, 2009).

Além disso, o e-commerce aproximou empresas ou criadores e seus clientes, tornando a negociação do produto mais prática e abrangente, com maior obtenção de dados e informações sobre eles a fim de estabelecer parcerias duradouras. O comércio online, assim, possibilita a análise das necessidades dos consumidores com o intuito de fidelizá-los.

A expansão da internet, dentre as diversas classes sociais e em territórios longínquos, possibilitará o surgimento de novos clientes a cada ano. A internet também otimiza os processos na empresa e possibilita a aberturas de novos mercados a nível nacional e internacional (TURBAN, 1999).

Sendo assim, o e-commerce tornou-se uma nova opção de vendas e distribuição para as empresas, visto que os consumidores estão usando cada vez mais os serviços online à medida que sua renda disponível aumenta, os pagamentos virtuais se tornam mais confiáveis e a variedade de fornecedores e formas de entrega se expande.

Ameaças externas como o surgimento de um vírus mortal, também remodelou a maior parte dos serviços ofertados. A pandemia provocada pelo Corona Virus Disease foi confirmada no dia 30 de janeiro de 2020 pela Organização Mundial de Sáude - OMS, o que

3VENTURA, Felipe. Restaurantes apontam dificuldades com iFood, Rappi e Uber Eats. 2020. Disponível em: https://tecnoblog.net/324471/restaurantes-apontam-dificuldades-delivery-ifoodrappi-uber-eats/. Acesso em: 13 abr. 2021

${ }^{4}$ UOL. Na pandemia, cliente do iFood fez 983 pedidos de comida em seis meses. 2020. Disponível em: https://economia.uol.com.br/noticias/redacao/2020/10/15/na-pandemia-cliente-doifood-fez-983-pedidos-de-comida-em-cinco-meses.htm. Acesso em: 13 abr. 2021 
provocou a queda das Bolsas de Valores em todo o mundo desde o seu início (SANTOS NETO, 2020).

A crise econômica promovida pela pandemia aprofundou-se rapidamente, com muitas atividades industriais e comerciais afetadas e, principalmente, microempresas enfrentando grandes dificuldades para retomarem às atividades. $O$ coronavírus, inevitavelmente, aumentará a recessão econômica dos continentes, desencadeando uma grave crise no sistema capitalista.

Sob uma visão pessimista da economia, há indícios de que companhias aéreas, empresas do agronegócio, aglomerados comerciais e empresas dos ramos de turismo e automobilismo não serão as mesmas após vários meses de lockdown (SANTOS NETO, 2020).

Nesse contexto caótico, causado pela pandemia, pensar no futuro da economia é analisar algumas características que estão exigindo uma mudança nas ideias e uma releitura de conceitos que norteavam a Economia Política e da Ciência Econômica desde o século XVIII.

Não obstante, a pandemia do novo Coronavírus pode ser extremamente relevante para repensar as formas convencionais de atrair capital e lucro. Apesar do desastre financeiro global, algumas empresas conseguiram manter e até expandir suas atividades na pandemia. A revista digital Época Negócios publicou, em setembro de 2020, as dez empresas que mais lucraram durante a pandemia: Amazon, Microsoft, Apple, Tesla, Tencent, Facebook, Nvidia, Alphabet, Paypal e T-mobile (ÉPOCA NEGÓCIOS, 2020).

Nesse sentido, Giffinger (2007) aborda o conceito smart para a economia, pois, segundo ele, com a maior competitividade econômica, urge a necessidade de promover a inovação, o empreendedorismo, a flexibilidade no mercado de trabalho, a produtividade, a readaptação, entre outros aspectos.

Sendo assim, é válido notar que ainda há margem de lucro para empresas capazes de modificar seu estilo de atuação, convertendo-o para o mundo digital. A Amazon, o Facebook, entre outras empresas, são grandes plataformas que estão evidenciando ainda mais o e-commerce e propiciando uma maior integração entre pequenas, médias e grandes empresas.

Nesse sentido, o final do milênio apresentou grandes inovações tecnológicas e científicas, o que exige ações pouco sedimentadas. Os casos fortuitos que ocorrem a nível mundial, requerem decisões rápidas e precisas em cenários diferenciados, inclusive, catastróficos.

No entanto, o comércio online também possui desvantagens, as quais devem ser analisadas pelas empresas e consumidores. Ferreira e Pitwak (2009) apresentam como um desses obstáculos o fato de que alguns consumidores gostam de tocar ou experimentar os produtos antes de realizar a compra, ou seja, não são todos os produtos que esses 
consumidores podem comprar pela internet. Outra grande desvantagem é a desconfiança por parte de alguns clientes em relação ao pagamento online, pois pode haver a insegurança de informar dados pessoais.

No que tange às empresas, Reedy e Schullo (2007) listam as seguintes desvantagens: falhas no sistema de compra e venda online e falhas na conexão da internet causando transtorno a empresa. Nesse sentido, será fundamental investir em ferramentas para evitar possíveis falhas e seus subsequentes prejuízos.

Cabe ressaltar que, para consumidores e empresas, existem riscos quanto à veracidade dos dados das partes negociantes, o que facilita os famosos "golpes" de ordem criminal. Outros obstáculos existentes no empreendimento online são as avarias no produto durante o trajeto à residência do consumidor, a falta de infraestrutura em algumas regiões do Brasil e as desigualdades sociais que reduzem o poder de compra de uma parcela da população (Arroyo et al, 2006).

Outro ponto de grande relevância para os restaurantes é a operação de entrega através de motoboys. Segundo reportagem da BBC Brasil, os restaurantes devem pagar uma taxa de $27 \%$ à plataforma caso optem por utilizar os entregadores do aplicativo; se essas empresas tiverem entregadores próprios a taxa é menor. Sendo assim, há uma considerável redução na margem de lucro (MADUREIRA, 2020).

\subsection{O Perfil do consumidor de delivery}

É necessário analisar as mudanças culturais e comportamentais causadas pela tecnologia. No que se refere ao alto número de pedidos de refeições por aplicativos, pode-se ressaltar a mudança do comportamento nas questões de gênero. Hoje, homens e mulheres tendem a compartilhar as mesmas obrigações nos afazeres domésticos, ou seja, com a entrada das mulheres no mercado de trabalho, muitos aspectos como cozinhar em casa deixaram de ser uma obrigação imposta pela sociedade ao gênero feminino.

O delivery é uma forma eficiente de ofertar ao consumidor conforto e eficiência; paralelamente, quando essa entrega é fomentada por empresas já consolidadas no mercado, como Ifood, Uber eats, entre outras, a tendência é gerar maior segurança, pois há a padronização e a garantia do processo de compra, desde a escolha do local à chegada da mercadoria.

Segundo a pesquisa do Instituto QualiBest (2019) -“Consumo de comida delivery por aplicativo", onde foram entrevistadas 2011 pessoas de todas as regiões do Brasil, homens e mulheres a partir de 19 anos e de todas as classes econômicas, foi identificado que entre os aplicativos e sites delivery, os de alimentação são os mais utilizados, com $49,78 \%$ dos 
entrevistados já tendo solicitado o delivery de comidas prontas. Além disso foi identificado que em média, os usuários gastam $\$ 38,00$ por refeição e costumam pedir delivery de comida nos finais de semana $(67,3 \%)$, quando querem algo que não sabem preparar $(56,0 \%)$ ou por falta de tempo para preparar uma refeição $(46,4 \%)$.

Ademais, o serviço pode se tornar uma vantagem competitiva, já que no comércio digital as interações com os clientes são limitadas, as empresas digitais devem focar em incrementar a experiência do consumidor, optando por embalagens que causem um impacto positivo, assim superando as expectativas dos clientes que fazem compras pela internet.

\subsubsection{O Impacto econômico do delivery}

A expansão da indústria do ramo alimentício através de delivery proporcionou oportunidades de emprego para muitas pessoas em uma variedade de tipos de emprego, incluindo chefs e funcionários administrativos em restaurantes, entregadores ou programadores por trás dos aplicativos / plataformas online.

Como citado anteriormente, essas cozinhas fantasmas não são abertas ao público no mundo físico e os pedidos online são sua única fonte de renda. Sendo assim, dispensar uma loja física tem muitas vantagens para restaurantes, incluindo uma redução de despesas com as instalações, redução de funcionários no ambiente, mobília etc., além de facilitar o aumento da diversidade de menus, conceitos ou mesmo marcas ${ }^{5}$.

Por se tratar de um negócio virtual, também há casos em que uma cozinha industrial abriga mais de uma marca, assim gerando uma economia de escala onde aproveitam a mesma infraestrutura para compor duas marcas diferentes que tenham sinergia e assim aumentar o alcance nos marketplace que estão inseridos. Como por exemplo o restaurante japonês "San Izakaya" no Rio de Janeiro, é um restaurante premium que utiliza a mesma cozinha para operar a marca secundária "Sushi One" onde se utiliza apenas as sobras de insumos da marca principal para conseguir ofertar um cardápio bem mais barato, atingindo um público-alvo distinto e fazendo um aproveitamento melhor das suas compras.

Além disso, os deliverys podem investir na logística de entrega, favorecendo o gerenciamento de entregas, permitindo-lhes estabelecer o delivery em tempo mais rápido e econômico.

${ }^{5} \mathrm{HANET}$, Isabelle. What is a dark kitchen? 2014. Disponível em: https://archive.is/ap9FB\#. Acesso em: 14 nov. 2020. 


\subsubsection{Impacto social do delivery}

O delivery impacta a relação entre os consumidores e seus alimentos, mudando a forma de se alimentar, bem como o preparo. Por sua vez, essas mudanças impactam na rotina de alguns indivíduos. Esta modalidade de consumo altera o comportamento de ir às compras, preparação e cozimento de alimentos em casa (Neumark-Sztainer et. al, 2010).

Em alguns casos, foi relatado que mulheres coreanas casadas são menos propensas a usar o delivery porque acreditam que têm a obrigação moral de preparar refeições para suas famílias $(\mathrm{ROH}, 2019)$.

Em contraste, outros estudos relatam que o delivery é visto por alguns consumidores chineses e britânicos como uma forma de obter refeições com facilidade, o que lhes permite passar mais tempo com a família (MEAH, 2017).

Existem diferentes pontos de vista sobre como o delivery afeta as relações sociais entre os jovens. Em um estudo com 365 alunos da Universidade de Ningxia, na China, constatou-se que $34,2 \%$ dos estudantes escolhem solicitar comida online por não ter com quem sair para comer; a suposição do autor era de que estudantes universitários não queriam se socializar (MA et al., 2019).

$\mathrm{Na}$ pesquisa qualitativa de Guangzhou também foi relatado que alguns jovens em início de carreira, embora dividam um apartamento com outras pessoas, também preferem pedir comida e consumi-las sozinhos em seus quartos. Esta prática foi atribuída ao fato de que muitos jovens na China levam uma vida independente e individualizada e não estão dispostos a se socializar (LIU et al., 2019).

Em geral, tem sido relatado que as pessoas tendem a compartilhar alimentos apenas com parentes próximos, como jovens casais que moram juntos, colegas que trabalham juntos ou estudantes que moram juntos em dormitórios. Dessa forma, o delivery proporciona uma mudança no convívio familiar e costumes, apresentando aspectos positivos e negativos.

\subsection{O Conceito de smart city e as implicações para a implementação de cidades inteligentes}

Para Barrionuevo et al. (2012) uma cidade inteligente deve reunir tecnologias que criam a integração de centros urbanos sustentáveis e habitáveis, de maneira coordenada e inteligente. Para os autores, os indicadores que contribuem para a inteligência de uma cidade são: econômico, ambiental, social, humano e institucional.

Já Caragliu et al. (2011) compreendem Smart City como uma cidade que investe em recurso humano e social através de infraestrutura de comunicação moderna, com vistas 
a obter qualidade de vida, crescimento econômico e combustível sustentável, com a devida participação governamental.

Morozov et al. (2019) definem as cidades inteligentes como o ápice da tecnologia das cidades; contudo, há predecessores que enfatizaram um conceito ecológico ao termo "smart", como a cidade eco-friendly, carbono-zero ou sustentável.

Ainda que os governos tenham decidido experimentar na prática uma cidade inteligente devido à emissão de poluentes e dos elevados custos de energia, as cidades continuarão a buscar soluções tecnológicas para suas deficiências, mesmo que isso resulte na ira de ambientalistas.

Nesse sentido, os autores Morozov e Bria (2019) entendem que as motivações para aplicação das smart cities foram classificadas em normativas e pragmáticas. As normativas estão relacionadas ao esforço de longa data para a implementação de tecnologias voltadas a atingir metas políticas ambiciosas e universalmente aceitas, como a desburocratização de diversos sistemas públicos e privados; o incentivo à participação política dos cidadãos comuns; e a criação de ambientes urbanos mais agradáveis e menos discriminatórios, capazes de fomentar o crescimento econômico, reduzir tensões e promover inovações.

As motivações pragmáticas abrangem uma complexidade de objetivos muito mais amplos e heterogêneos. Algumas cidades buscam empreender tecnologicamente por suas promessas de imensa economia no fornecimento de serviços similares ou melhores durante épocas de cortes orçamentários e crises econômicas.

Outras cidades buscam o aprimoramento tecnológico devido aos megaeventos, como as Olimpíadas, com a justificativa de reforçar o policiamento e a segurança dos cidadãos. Atualmente, as câmeras smart possibilitam um maior controle de áreas que até então eram de difícil acesso.

O conceito de smart city desponta, portanto, com grande relevância nas pautas globais, tendo como base as soluções tecnológicas e o uso de produtos e serviços inteligentes a fim de manter o crescimento econômico e as demandas da classe média nas áreas metropolitanas.

Denise Vogel (2020) cita a sociedade 5.0, um conceito que teve início entre os anos 2016 e 2017 na Alemanha e que se estendeu rapidamente por outros países europeus e asiáticos. Esse modelo de sociedade seria fundamentado em tecnologias como big data e inteligência artificial, elaboradas para solucionar as necessidades humanas.

A autora Denise Vogel (2020), por sua vez, faz um alerta sobre a cidade do século $\mathrm{XXI}$, principalmente as pertencentes aos países emergentes, onde se vê muita desigualdade social e segregação. 
Não se pode falar em desenvolvimento de cidades inteligentes sem levar em consideração as dificuldades de implementação de novas tecnologias no Brasil, isso porque há uma grande parcela da população de baixa renda e sem acesso à internet ou mesmo sem acesso a cartões de crédito ou débito para pagamentos virtuais.

A autora reforça a ideia de que ainda há muitos brasileiros vivendo as mazelas sociais, as quais evidenciam a falta de investimento público em educação, saneamento básico, coleta de lixo, saúde, entre outros. Portanto, para se implementar uma smart city, deve-se eliminar os obstáculos de caráter social e econômico vivenciados, principalmente, nos países em desenvolvimento.

\subsubsection{Dark Kitchen como uma inovação smart}

Dark Kitchen é uma nova modalidade de restaurante que oferece apenas serviço de entrega de comida, isto é, Delivery ou drive-thru. Como abordado no presente trabalho, neste tipo de empresa não há espaço para refeição; é um negócio estritamente para entrega, com aparato de uma cozinha industrial. O objetivo final é fornecer os pedidos requisitados pelos clientes através de aplicativos de dispositivos móveis ou ligações telefônicas.

No conceito de Vogel (2020), as smarts cities devem apresentar uma forte integração no uso dos espaços físicos e cibernéticos. E por que a "Dark Kitchen" encontra respaldo nesse conceito? Ora, o uso do espaço físico nessa modalidade é aproveitado de maneira inteligente, tendo em vista que esse modelo de restaurante fantasma só existe no mundo virtual, portanto, acaba sendo mais importante encontrar uma localização estratégica de distribuição que tenha um espaço suficiente, em vez de um espaço amplo para receber os clientes.

Mas, nem por isso, deixam de atrair uma forte clientela. Num passado não tão distante, essas cozinhas existiam num baixo percentual, mas, com o atual momento, esse modelo de restaurante ganhou força e espaço no ramo de entregas em domicílio. Os profissionais que trabalham na cozinha a utilizam de maneira segura apenas para entregar o melhor para os consumidores que, atualmente, encontram restrições para saírem de suas casas.

Além disso, o custo-benefício para o empreendedor é atraente, tendo em vista que não há que se falar em gastos com estrutura de salão, utensílios para alimentação, decoração e instalação em geral, além de os aluguéis de espaços serem mais baratos do que em pontos comerciais mais atrativos, como ruas de comércio e shoppings. Nesse sentido, o autor João Yanase (2018, p. 23) revela-nos o conceito de custo que é "o gasto em bens ou serviços 
empregados para produzir outros bens ou serviços". E investimento pode ser definido como "gasto que foi 'ativado' e que promoverá benefícios ao longo de diversos anos, durante sua vida útil.".

Sendo assim, a Dark Kitchen se tornou um negócio atrativo, pois, segundo a Associação Brasileira de Bares e Restaurantes - Abrasel, há um crescimento constante do mercado de delivery, em média $20 \%$ ao ano, o que cria um novo formato de operação que torna irrelevante o investimento em um ponto de vendas com as portas abertas à população. Em levantamento feito pela Associação, é possível notar que em 2019 o mercado de entrega nacional faturou $R \$ 15$ bilhões de reais e em 2020 a expectativa é atingir $R \$ 18$ bilhões de reais. (ABRASEL, 2020)

Célio Salles, membro do Conselho de Administração Nacional da Abrasel, relata que o aumento é devido ao uso de aplicativos em dispositivo móvel, o que demonstra a mudança do comportamento do consumidor. Segundo o professor Roberto Kanter da Fundação Getúlio Vargas, os aplicativos possibilitam uma comunicação maciça, demandas e promoções que um restaurante, isoladamente, teria muitas dificuldades de cumprir (ABRASEL, 2020).

David L. Rogers (2017) afirma que não há motivos para que empresas digitais novatas superem as empresas tradicionais. Algumas empresas tradicionais ainda podem ditar as regras atualmente, porém, seus administradores, frequentemente, não possuem meios adequados para compreender e, então, enfrentar os desafios competitivos da era digital presente nas smart cities.

Dentro do conceito smart, a população passou a experimentar a funcionalidade dos smartphones que são celulares com muitos recursos funcionais e alto processamento de dados. A utilização de aplicativos nesses aparelhos se tornou parte da rotina do ser humano.

Ressalta-se que o mercado de aplicativos apresenta uma constante crescente de downloads e usuários. Em um estudo feito pelo Instituto Locomotiva ${ }^{6}$, divulgado no dia 29 de abril de 2020 , houve um crescimento de $30 \%$ em compras feitas por meio de aplicativos em solo brasileiro. Além disso, cerca de $32 \%$ das pessoas abordadas pelo Instituto relataram que planejam reduzir as idas às lojas físicas.

Nesse contexto, é válido salientar que a pandemia de 2020 impôs enormes mudanças no cotidiano da população urbana: os cidadãos foram compelidos a ficar em casa mudando totalmente a rotina de trabalho, que passou a ser home office; a comida passou a ser pedida por aplicativos ou por sites de empresas que oferecem serviço de entrega.

${ }^{6}$ BOND, Letycia. Compras por aplicativos têm alta de $30 \%$ durante pandemia, diz pesquisa. 2020 . Disponível em: https://agenciabrasil.ebc.com.br/economia/noticia/2020-04/compras-poraplicativos-tem-alta-de-30-durante-pandemia-diz-pesquisa. Acesso em: 13 out. 2020. 
Sendo assim, o perfil de usuário de tecnologia ou consumidor tem sofrido alterações diante das necessidades, mudanças ou caso fortuito que ocorrem no mundo. Para o empreendedor é de extrema importância analisar o perfil e as demandas dessa sociedade, como bem afirma o autor David Rogers (p.10, 2017):

A função tradicional do executivo-chefe de informação era usar a tecnologia
para otimizar processos, para reduzir riscos e para melhorar a gestão dos
negócios existentes. A função emergente do executivo-chefe de atividades
digitais é muito mais estratégica, focada no uso da tecnologia para reimaginar
e reinventar o core business (negócio principal) em si. (ROGERS, p. 10, 2017)

A complexidade da implementação de uma smart city não se baseia apenas em grandes aplicativos como Uber e Airbnb; outras organizações estão encontrando formas de lucrar ante a estagnação da economia global. As cidades, por sua vez, ficam suscetíveis à privatização de sua infraestrutura e mais ainda precisam das soluções dadas por companhias como o Google para fazer funcionar os recursos e bens sob controle público.

A proposta da Dark Kitchen não é diferente. Após o ápice da pandemia, o poder público teve que remodelar a prestação de serviços na esfera privada, isto é, o governo estadual teve que preparar a infraestrutura no ramo alimentício e farmacêutico, visando impedir gargalos, que ocorre quando a capacidade é menor do que a demanda.

Nesse sentido, os serviços solicitados por inteligência artificial podem ser utilizados para otimizar o funcionamento e a operacionalização das cidades metropolitanas. Os problemas diários enfrentados pela cidade a lança aos braços das empresas de tecnologia com o objetivo de ofertar produtos ou serviços essenciais e únicos. Assim, os centros urbanos embarcam em ondas sucessivas de privatização com o objetivo de cortar gastos.

\subsubsection{Dark Kitchen: Redução nos custos e formação de preços de venda}

Segundo João Yanase (2018, p.16), "o preço de venda pode ser calculado pela apuração do custo e, a ele, agregado outros custos e despesas decorrentes das vendas.". Cabe ressaltar que a venda requer despesas com logística, seguro, financiamentos, impostos, dentre outros. A venda também deve atenuar despesas gerais, chamadas de "despesas fixas" e as despesas administrativas, além de reembolsar o capital investido.

A apuração dos custos tem extrema importância para que os gestores administrem o negócio conforme a receita e os custos. Assim, para o ramo industrial, o custo de um produto envolve matéria-prima, insumos, embalagens, mão de obra e custos indiretos de produção. No caso da atividade comercial, a apuração dos custos será mais simples, pois será adicionado ao preço da mercadoria as despesas como frete, custo financeiro, seguro, etc., chamadas de despesas acessórias (YANASE, 2018). 
Já nas atividades de serviços, dependendo da complexidade, também não há grandes obstáculos, uma vez que o custo é composto pelo gasto com a mão de obra direta e com os materiais empregados. Obviamente, o cálculo do preço de venda de um produto, serviço ou mercadoria será aplicado após sua apuração.

Para isto, Yanase (2018) apresenta as seguintes etapas: apuração do custo, cálculo em percentual dos impostos incidentes (despesas tributárias); cálculo em percentual das despesas comerciais, como frete, comissão e seguro (despesas comerciais); cálculo em percentual do custo financeiro, uma vez que, normalmente, as vendas são financiadas pela empresa (despesas financeiras); definição do percentual da margem de lucro desejável (margem - Mg); cálculo do percentual do "custo fixo" ou das "despesas estruturais" em relação ao volume das receitas (custos fixos - CF).

Após essas etapas, é possível averiguar a formação do preço de venda do produto partindo das informações hipotéticas como o custo do produto; impostos incidentes; despesas comerciais; custo financeiro; margem desejada; e custo fixo ou despesas estruturais.

Conforme descrito no tópico anterior, o restaurante fantasma é um ramo voltado para entregas em domicílio. Nesse tipo de restaurante, é dispensável a existência de garçons, mobília, despesas com decoração, isto é, promove-se uma redução dos custos indiretos. Segundo Yanase (2018, p.52) os custos indiretos:

Representam os custos incorridos no ambiente da fábrica e que não estão diretamente relacionados com certo produto e sim com a unidade fabril como um todo. Eles não se relacionam diretamente com o produto, porém são necessários para que a unidade fabril cumpra seu papel: produzir os produtos.

Tabela 1: Custos indiretos de empresas de entregas em domicílio.

$\begin{array}{lr}\text { Aluguel e imposto predial } & \$ 8.000,00 \\ \text { Energia elétrica } & \$ 1.200,00 \\ \text { Água e esgoto } & \$ 300,00 \\ \text { Telefone e internet } & \$ 3.500,00 \\ \text { Seguro patrimonial } & \$ 3.000,00 \\ \text { Higiene e limpeza } & \$ 4.000,00 \\ \text { Salários e encargos, exceto comissão } & \$ 25.000,00 \\ \text { Manutenção geral } & \$ 1.500,00 \\ \text { Depreciação } & \$ 2.000,00 \\ \text { Material de expediente } & \$ 2.000,00 \\ \text { Embalagens (sacolas, caixas, sacos } & \$ 3.000,00 \\ \text { plásticos, fitas) } & \\ \text { Uniforme } & \$ 1.000,00 \\ \text { Soma } & \$ 54.500,00\end{array}$

Fonte: Yanase, 2018 
Larissa Coldibeli (2020) afirma que as Dark Kitchen são, atualmente, a principal estratégia de expansão das franquias do ramo alimentício. Em uma pesquisa feita pela $A B F$ (Associação Brasileira de Franchising), aponta-se que essa modalidade de restaurante impulsiona a economia através da expansão de redes, atração de novos empresários, mesmo em um cenário caótico.

Para exemplificar, O restaurante L'Entrecôte de Paris, da holding de franquias SMZTO, apostava nos modelos tradicionais de restaurantes, os quais exigiam investimento de aproximadamente $\mathrm{R} \$ 1.5$ milhão. Contudo, em abril de 2020, inaugurou-se a primeira Dark Kitchen no bairro Anália Franco, no estado se São Paulo, O investimento, por sua vez, ficou entre $R \$ 100$ mil e $R \$ 150$ mil reais.

O gerente de operações, Rodrigo Diotto, afirma que a expectativa é ainda abrir oitenta lojas no modelo Dark Kitchen (COLDIBELI, 2020). Diante de tais informações, verificase que o custo para aplicação de uma Dark Kitchen é $10 \%$ (dez por cento) do valor que seria estabelecido para implementação de um restaurante tradicional.

Outra franquia que assumiu o modelo foi a Burger King e Popeyes Louisiana Kitchen. Através de documento oficial de assessoria, comunicou que no terceiro trimestre de 2020 suas filiais retomaram os serviços e que, em 20 de agosto de 2020, a Companhia iniciou a primeira operação Ghost Kitchen, integrando as duas marcas citadas (MALHEIROS, 2020).

Esse modelo de restaurante promete permitir o alcance de novos públicos, promovendo uma espera no conforto de casa e, ainda, terá uma verdadeira redução nos custos. Ademais, possibilita o surgimento de novos empreendedores ante aos novos costumes impostos na sociedade durante um momento pandêmico. O pós-pandemia também concederá uma estabilidade ao negócio, visto que o perfil do consumidor tende a se manter com o decorrer do tempo. 


\section{Metodologia}

\subsection{Tipo de pesquisa}

O presente trabalho analisa as oportunidades voltadas aos restaurantes que passaram a se dedicar somente ao mundo virtual, no modelo dark kitchen. Para tanto, fez-se um levantamento bibliográfico sobre conceitos inovadores que vêm se expandindo no mundo dos negócios. O autor deste trabalho, é um dos sócios fundadores da dark kitchen "Uni Sushi" que serviu de inspiração para o tema, assim como forneceu uma série de documentos que serviram como uma importante fonte de dados para a elaboração deste trabalho.

Realizou-se também, entre os meses de abril a junho de 2021, uma pesquisa exploratória, que envolve 2 entrevistas realizadas com administradores de dark kitchens, no município do Rio de Janeiro, a fim de obter uma melhor compreensão da visão destes empreendedores sobre como foi o processo de decisão para abrir uma dark kitchen, como a pandemia afetou as suas vendas, assim como os desafios e vantagens desta modalidade.

\subsection{Coleta de dados}

Além de todo levantamento bibliográfico realizado, foi elaborado um roteiro semiestruturado com perguntas abertas e direcionadas a dois administradores de dark kitchen. Inicialmente, tem-se o restaurante Uni Sushi que opera delivery de comida asiática para empresas e para consumo domiciliar. A empresa foi aberta no dia 15 de agosto de 2019 . Administrada por Johnson Hsu e João Victor Medawar, está em funcionamento há 1 ano e 7 meses em Copacabana. O restaurante começou suas vendas em 13 de novembro de 2019, antes do início da quarentena.

A ideia de abrir a empresa "Uni Sushi", surgiu a partir da ideia de fornecer uma culinária japonesa de alta qualidade com preços acessíveis, foi decidido abrir no bairro de Copacabana, por ser um bairro central da Zona Sul do Município do Rio de Janeiro, facilitando a logística das entregas e também pelo fato de não terem dark kitchen com essa proposta na Zona Sul carioca. Outro fator importante, foi que além da grande concorrência não há muitas barreiras de entrada neste segmento, o processo de abertura é muito menos burocrático do que um restaurante, a operação é simplificada, já que não há necessidade de funcionários para fazer o atendimento presencial, e os custos fixos são reduzidos. A modalidade de dark 
kitchen também é muito mais segura em relação a mudanças no ambiente externo, fator esse que foi de extrema importância durante a crise sanitária do COVID-19.

A dark kitchen em análise necessitou de um investimento inicial de $\$ 228.000,00$ para a sua abertura, possui mobiliário para produção de culinária japonesa, contando com apenas 8 funcionários, sendo estes o chefe sushiman, o auxiliar de sushiman, chefe de cozinha, atendente para operar o caixa e despachar pedidos e conta com um serviço terceirizado de entregas, em que são contratados de 5 a 7 motoboys por dia, de acordo com a demanda. O restaurante participa, integralmente, da produção do alimento, porém a entrega é feita através dos motoboys da empresa Rodrigues Expresso.

O Uni Sushi, está situado nos seguintes canais de venda:

$>\quad$ Aplicativo próprio

$>\quad$ Site

$>\quad$ Ifood

$>$ Rappi

$>\quad$ Uber Eats

$>\quad$ Telefone / Whatsapp

Todas essas plataformas geram uma média de 1.300 pedidos ao mês, com um ticket médio de \$110,00 por pedido. Segundo seus sócios, o Uni Sushi conseguiu atingir este número de pedidos mensais, em parte, por causa da quarentena praticada pelos moradores do Rio de Janeiro durante esta pandemia.

Outra dark kitchen pesquisada foi a Noir Pizzaria, administrada por João Victor Betencourt, situada no bairro da Tijuca, Zona Norte do Município do Rio de Janeiro. A empresa foi aberta em 22 de outubro de 2020, e começou suas vendas no mês de março de 2021, durante a quarentena.

A ideia de abrir a Noir Pizzaria, veio pela paixão por pizza pelo dono da marca e pela carência de uma pizza artesanal de qualidade no bairro. Além disso, ele se aproveitou do momento de quarentena, onde o segmento de delivery estava em alta. Como era o primeiro empreendimento do entrevistado, ele disse que optou por fazer na modalidade de dark kitchen para mitigar os seus riscos devido à falta de experiência, já que o investimento inicial é substancialmente menor e a operação mais simples de gerir.

A Noir Pizzaria contou com um investimento inicial de $\$ 75.000,00$ para dar início a sua operação, conta com equipamentos de cozinha industrial focado na produção de massas de fermentação natural, conta com um confeiteiro para confecção dos doces da loja, que inclusive está sendo revendido em outras lojas parceiras. Além disso, por operar apenas no turno da noite, conta apenas com um pizzaiolo responsável pelo mise en place e a produção dos pedidos, e um atendente para receber e despachar os pedidos. A Noir Pizzaria, 
a fim de simplificar ainda mais sua operação, contratou a empresa Dinâmica Motos para fazer o seu serviço de entregas, com 2 motoboys trabalhando em turnos de 6 horas cada.

Diferente do Uni Sushi, a Noir Pizzaria, conta com apenas dois canais de venda, iFood e o Whatsapp. Totalizando em uma média de 650 pedidos ao mês com um ticket médio de $\$ 90,60$ por pedido. O entrevistado acredita que esta média de pedidos se apoia no fato dele ter começado a sua operação durante a quarentena e feito grandes investimentos em marketing para sua divulgação.

Para a coleta de dados, foi elaborado um roteiro semiestruturado (Anexo 2) para servir como guia das perguntas a serem feitas, a fim de entender a visão do gestor em relação às dark kitchens e as características de suas empresas. Em função da pandemia, as entrevistas foram realizadas por telefone, gravadas e posteriormente transcritas para facilitar o processo de análise de dados. Foram tratados temas como: o processo de decisão para abrir uma dark kitchen; como uma crise sanitária como a do COVID-19, afetou as vendas; as vantagens e desafios de se ter uma operação de dark kitchen; como funciona a operação do empreendimento. 


\section{Análise dos dados}

Os dados foram analisados conforme a análise de conteúdo, como proposta por Bardin (2011). Os temas das entrevistas foram agrupados por eixos temáticos, assim como indicadores foram elaborados para orientar a interpretação das informações fornecidas, então foram feitas comparações entre ambas as empresas, analisando as diferenças entre as dark kitchens e a visão dos gestores entrevistados.

\subsection{Comparação entre os estabelecimentos}

Os empreendimentos Noir Pizzaria e Uni Sushi, dark kitchens situadas na Zona Norte e Zona Sul do Rio de Janeiro, respectivamente, contaram com um investimento inicial substancialmente diferente, apesar de serem empreendimentos parecidos. Enquanto a Noir Pizzaria precisou de um investimento de $\$ 75.000,00$, o Uni Sushi necessitou aportar $\$ 228.000,00$ para tirar o seu projeto do papel, ou seja, um valor três vezes maior. Isto se deve principalmente, por causa da diferença entre as culinárias italianas e japonesas, onde a japonesa tem insumos mais caros e precisa de uma cozinha industrial bem equipada com equipamentos como panelas de arroz e facas importadas do Japão, freezers horizontais, balcão de inox refrigerado, vitrine para peixes, entre outros aparatos. Além disso, o capital de giro inicial para a compra do estoque é bem elevado. Em contrapartida, na Noir Pizzaria, o entrevistado cita que o único equipamento com custo significativo foi o seu forno elétrico que custou $\$ 12.000,00$ e é capaz de produzir 2 pizzas em 90 segundos.

Apesar de seu horário de funcionamento ser reduzido em comparação ao Uni Sushi, a Noir Pizzaria conta com uma equipe de apenas 5 funcionários, enquanto a outra precisa de 15 trabalhadores, incluindo os motoboys que ambas as empresas optaram por terceirizar.

O Uni Sushi está aberto há mais tempo e já se consolidou em mais canais de venda do que a Noir Pizzaria, isto fica evidente quando é comparado o volume de pedidos ao longo do mês: enquanto o japonês vende uma média de 1.300 pedidos, a pizzaria faz metade 
disto, com cerca de 650 pedidos. Apesar do Uni Sushi ter um horário de funcionamento maior, o entrevistado cita que a maior parte de suas entregas ainda acontecem no período da noite.

Outro ponto interessante é que ambas as marcas se apoiaram no período de quarentena para se estabelecer no mercado, como o Uni Sushi abriu logo antes da pandemia ele pode pegar este movimento desde o início, enquanto a Noir Pizzaria abriu tardiamente, o entrevistado ainda acha que o crescimento no setor de delivery foi importante para o crescimento de sua marca.

\subsection{Vantagens e desvantagens do delivery}

Através dos dados coletados nas entrevistas emitidas aos gestores das dark kitchens, na cidade do Rio de Janeiro, observou-se as vantagens e desvantagens do empreendimento:

Tabela 2: Vantagens e desvantagens da dark kitchen

\begin{tabular}{|c|c|}
\hline Vantagens & Desvantagens \\
\hline $\begin{array}{l}\text { Possibilidade de operar mais de uma } \\
\text { marca em um espaço único otimizado }\end{array}$ & $\begin{array}{l}\text { Altas taxas nos serviços ofertados pelos apli- } \\
\text { cativos de marketplace; }\end{array}$ \\
\hline $\begin{array}{l}\text { Investimento inicial menor em relação ao } \\
\text { restaurante tradicional }\end{array}$ & $\begin{array}{l}\text { Dificuldade em manter um bom relaciona- } \\
\text { mento com os clientes. }\end{array}$ \\
\hline $\begin{array}{l}\text { Despesas de pessoal reduzida em relação } \\
\text { ao restaurante tradicional }\end{array}$ & Custo de embalagens elevado; \\
\hline $\begin{array}{l}\text { Pouca barreira de entrada para novos em- } \\
\text { preendedores }\end{array}$ & $\begin{array}{l}\text { Custos na contratação e manutenção de moto- } \\
\text { boys; }\end{array}$ \\
\hline
\end{tabular}

Como vantagem, podemos citar que a operação é simplificada e o custo da dark kitchen é reduzido, assim sendo mais fácil de fazer uma operação lucrativa. Outra vantagem interessante e única das dark kitchens é a possibilidade de abrir mais de uma marca no mesmo estabelecimento, o que possibilita diversas vantagens competitivas, como maior exposição nas plataformas de marketplace, cálculo de impostos mais eficientes já que com dois ou mais CNPJs, o faturamento é fracionado, assim permanecendo nas faixas de cálculo que pagam menos imposto, e além disso, é possivel fazer um maior aproveitamento dos seus insumos que vão estar sendo utilizados em mais de um cardápio.

Uma desvantagem do serviço de delivery que foi relevante para ambos os entrevistados, é a dificuldade em configurar uma boa logística de motoboys com o seu elevado 
custo. Tanto o Uni Sushi quanto a Noir Pizzaria, optaram por terceirizar este serviço para simplificar a sua operação, já que é elevado o risco de processos e acidentes de percurso.

Além de ser difícil encontrar motoboys que prezem pela qualidade da entrega, tomando cuidado para o pedido não ser danificado no percurso, o custo de manutenção dos mesmos é dos mais relevantes do negócio, já que junto ao salário base do entregador, é necessário pagar: aluguel da moto, taxa de periculosidade de $30 \%$ sob o salário base, plano de saúde, seguro de vida e a gasolina gasta no percurso.

Dessa forma, as dark kitchen, devem dar grande atenção para montar uma logística eficiente de entregas, para que não fiquem reféns das elevadas taxas dos grandes aplicativos de marketplace. Assim como devem fazer um grande investimento em embalagens para incrementar a experiência do cliente ao receber o seu produto e minimizar o risco de danos durante o transporte.

Embora as vantagens de uma operação dark kitchen sejam fáceis de identificar, ainda é necessário enfrentar alguns desafios, como as barreiras de entrada do segmento, sendo a mais relevante a alta concorrência já que existe, tendo em vista que uma série de empresas já estão consolidadas no ramo gastronômico. Para superar isso é necessário se diferenciar para conseguir uma parcela relevante de marketshare.

É necessário continuar a refletir sobre as peculiaridades do momento atual e questionar como as atividades comerciais em geral podem ser conduzidas de forma mais prática, produtiva e benéfica para todos os envolvidos.

\subsection{Importância dessa análise para a execução do trabalho}

Diante de todo referencial teórico já exposto, a revista Exame publicou, em 10 de agosto de 2020, que as empresas ou setores que lucraram durante a pandemia estão indo na contramão de uma suposta crise econômica. Para o estudo realizado, o lockdown impôs a necessidade de entregas para que o produto ou o serviço chegue ao consumidor. (CORREIA, 2020)

Sendo assim, o iFood atingiu uma média de um milhão de entregas por dia no mês de março de 2020. Além da entrega de comida que era, costumeiramente, solicitada, esse tipo de aplicativo começou a oferecer outros produtos que antes não estavam disponíveis, inclusive a alta gastronomia de renomados chefes de cozinha (CORREIA, 2020).

Nesse sentido, não foi só o aplicativo de delivery que lucrou, mas também as empresas associadas a ele. Sendo assim, podemos entender que diversos fatores possibilitaram o lucro do restaurante como a vigência de leis que favoreceram o fortalecimento 
da operação de delivery; a popularização do uso de aplicativos para compra e venda, no interior e nas áreas urbanas; ampla concorrência e competitividade.

Além disso, foi importante a perspectiva de empreendedores que estão imersos neste mundo para apresentarem seus pontos de vistas e experiências adquiridas. Entender o que eles viram como oportunidade, assim como os desafios enfrentados. Também entender o funcionamento de sua operação e como eles tiram vantagens de seu modelo de negócio para formar um empreendimento bem-sucedido.

Vale ressaltar que, ambos entrevistados estão bem otimistas com o futuro da modalidade, e acreditam que este é apenas o início de um segmento que vai ganhar muita relevância no futuro, impactando a maneira das pessoas de se alimentarem.

\subsection{Limitações do estudo e projetos futuros}

Primeiramente, é importante observar que, embora o escopo da revisão seja de natureza global, a modalidade Dark Kitchen é mais forte nos países desenvolvidos, o que significa que o tema possui maior número de pesquisas em línguas e contextos estrangeiros, sendo pouco aprofundado no Brasil. Espera-se que, futuramente, surjam mais estudos, artigos e regulamentações para que essa modalidade seja explorada em países emergentes como o Brasil.

Como este é um campo acadêmico em expansão, deseja-se que futuros pesquisadores adotem uma abordagem sistêmica para entender os impactos de sustentabilidade da entrega de refeições em domicílios ou ambiente empresariais. A pesquisa até o momento abordou as vantagens e desvantagens do delivery, bem como motivações dos empreendedores para investir neste segmento.

Para estudos futuros, é interessante abordar se a modalidade dark kitchen poderá se sobrepor ao restaurante tradicional devido ao novo comportamento do consumidor e às novas restrições geradas por pandemias como a do COVID-19. 


\section{Considerações Finais}

O trabalho apresentou a expansão do e-commerce no Brasil, abordando a nova modalidade de cozinha fantasma na indústria alimentícia. Salienta-se que os teóricos analisaram que, para garantir a sobrevivência no mundo dos negócios, é necessário acompanhar as exigências e o perfil de compra dos clientes, que cada vez mais utilizam a internet para realizar diversas atividades, que vão desde entretenimento e compras até a busca por relacionamentos.

Para a consolidação das empresas de delivery, é necessário desenvolver a infraestrutura embutida no conceito de smart city, que exige melhorias contínuas em logística, nas plataformas digitais, nas formas de pagamento, na segurança de dados e no comprometimento em atender e satisfazer às necessidades da população.

Analisou-se as entrevistas realizadas com donos de dark kitchens para obter insights sobre o segmento, identificar as peculiaridades da operação assim como as vantagens e desvantagens que eles levaram em consideração para tomar a decisão de investir neste projeto. Este modelo empreendimento se tornou muito relevante diante do cenário do COVID-19, sendo uma ótima oportunidade de crescimento enquanto outros setores estavam em queda, já que o conceito de compra online foi muito desmistificado durante este período em que as pessoas tiveram que mudar seus hábitos para se adaptarem a uma restrição imposta.

Indiscutivelmente, a indústria do delivery tem sido muito proativa na forma como o mercado se desenvolve e cultiva novos hábitos alimentares dentre os consumidores. Além disso, possibilitou novos empreendimentos, onde não há a necessidade de se ter uma loja física aberta ao público, a chamada dark kitchen.

Acredita-se existir uma forte tendência de crescimento da modalidade durante e após a pandemia do COVID-19. Sendo assim, terá oportunidade para muitos empreendedores explorarem este segmento como uma fonte de renda, e também como um primeiro passo na jornada empreendedora, já que conta com um investimento inicial relativamente menor e uma complexidade operacional mais fácil de gerir.

Mesmo com a forte tendência, a opção pela dark kitchen precisa ser pensada dentro da estratégia do negócio, pensando em aspectos como: relacionamento com clientes, estrutura de entrega, investimentos, planejamento do espaço físico. Neste sentido, enquanto o serviço de delivery se coloca como uma alternativa com baixo investimento, concorre com 
uma série de empreendimentos que também nasceram na pandemia, e que estão nas mesmas plataformas de marketplace.

Assim, como foi apresentado, o futuro da entrega de comida online é otimista, mas também é importante assegurar que o setor se desenvolva de modo sustentável e que atenda aos interesses da sociedade. 


\section{Referências Bibliográficas}

ALBERTIN, Alberto. Evolução do Comércio Eletrônico no Mercado Brasileiro. Anais do BALAS, 2000.

ARROYO, Cristiane Sônia et al. Uma análise das preferências de consumidores no comércio eletrônico. Facep Pesquisa: Desenvolvimento e gestão, Franca, v. 9, n. 1, p. 5-16, mar. 2006. Disponível em: http://periodicos.unifacef.com.br/index.php/facefpesquisa/article/view/62/128. Acesso em: 15 nov. 2020.

Associação Brasileira de Bares e Restaurantes. Do celular à mesa: como os apps de delivery transformam o mercado de bares e restaurantes. Disponível em: https://abrasel.com.br/noticias/noticias/do-celular-a-mesa-como-os-apps-de-delivery-transformam-o-mercado-de-barese-restaurantes/. Acesso em 26 de out 2020.

BARNEY, Jay B; HESTERLY, William S. Administração Estratégica e Vantagem Competitiva. 2. ed. São Paulo: Pearson Universidades, 2007. 432 p.

BARRIONUEVO, Juan Manuel; BERRONE, Pascual; COSTA, Joan Enric Ricart. Smart Cities, Sustainable Progress: opportunities for urban development. lese Insight, [S.L.], v. 14, n. 14, p. 50-57, 15 set. 2012. Universidad de Navarra. http://dx.doi.org/10.15581/002.art-2152.

BITTENCOURT, Andréa Gomes. Valores, atitudes e comportamentos gerenciais requeridos pelo processo de globalização e as diretrizes para as ações de desenvolvimento de recursos humanos. 1998. 142 f. Dissertação (Mestrado) - Curso de Administração, Centro de Formação Acadêmica e Pesquisa, Faculdade Getúlio Vargas, São Paulo, 1998. Disponível em: https://bibliotecadigital.fgv.br/dspace/handle/10438/3324. Acesso em: 30 nov. 2020.

BOND, Letycia. Compras por aplicativos têm alta de $30 \%$ durante pandemia, diz pesquisa. 2020. Disponível em: https://agenciabrasil.ebc.com.br/economia/noticia/2020-04/compras-por-aplicativos-tem-alta-de-30-durante-pandemia-diz-pesquisa. Acesso em: 13 out. 2020.

CARAGLIU, Andrea et al. Smart Cities in Europe. Journal Of Urban Technology, [S.L.], v. 18, n. 2, p. 65-82, abr. 2011. Informa UK Limited. http://dx.doi.org/10.1080/10630732.2011.601117.

CARVALHO, Eduardo Ramos de. E-commerce Brasileiro, a velocidade do crescimento. 2013. Disponível em: https://www.ecommercebrasil.com.br/artigos/e-commerce-brasileiro-avelocidade-do-crescimento/. Acesso em: 15 set. 2020.

CARNEIRO, Henrique. Comida e sociedade: uma história da alimentação. Rio de Janeiro: Campus, 2003.

COLDIBELI, Larissa. Mais baratas, dark kitchens aceleram expansão de franquias de alimentação. 2020. Disponível em: encurtador.com.br/ltAS9. Acesso em: 18 abr. 2021 
CORREIA, Beatriz. Examinado: crise para quem? setores que lucram durante a pandemia. crise para quem? Setores que lucram durante a pandemia. Exame. Disponível em: https://exame.com/videos/examinando/examinando-crise-para-quem-setores-que-lucram-durante-a-pandemial. Acesso em: 12 out. 2020.

Época Negócios. As 10 empresas que mais cresceram durante a pandemia do coronavírus. 2020. Disponível em: https://epocanegocios.globo.com/Empresa/noticia/2020/06/10-empresas-que-mais-cresceram-durante-pandemia-do-coronavirus.html. Acesso em: 28 nov. 2020.

FRANÇA, Ivanir. Pesquisa: qual o aplicativo de delivery mais utilizado no interior do Brasil. 2021. Disponível em: https://blog.deliverymuch.com.br/aplicativo-de-delivery-maisutilizado-no-brasil/. Acesso em: 16 abr. 2021

G1, Globo. Coronavírus: o impacto na economia chinesa, e por que isso é uma grande ameaça ao mundo. o impacto na economia chinesa, e por que isso é uma grande ameaça ao mundo. 2020. Disponível em: https://g1.globo.com/economia/noticia/2020/03/22/coronaviruso-impacto-na-economia-chinesa-e-por-que-isso-e-uma-grande-ameaca-ao-mundo.ghtml.

Acesso em: 01 nov. 2020.

GIFFINGER, Rudolf et al. Smart cities: ranking of european medium-sized cities. Vienna University Of Technology, Vienna, v. 16, n. 1, p. 1-25, jan. 2007.

HADDAD, Paulo R. Uma introdução à economia do século XXI. São Paulo: E-Galáxia, 2018. 437 p.

HOFRICHTER, Markus. Análise SWOT: quando usar e como fazer. Porto Alegre: Simplíssimo, 2017. $38 \mathrm{p}$.

IGREJA, Arthur. Conveniência é o nome do negócio: descubra como facilitar a jornada dos seus consumidores e multiplicar seus resultados. São Paulo: Planeta Estratégia, 2019. 146 p.

Instituto Brasileiro de Geografia e Estatística. Uso de Internet, televisão e celular no Brasil. 2019. Disponível em: https://educa.ibge.gov.br/jovens/materias-especiais/20787-uso-de-internet-televisao-e-celular-no-brasil.html. Acesso em: 13 nov. 2020.

LIU, Chen; CHEN, Jiaxi. Consuming takeaway food: convenience, waste and chinese young peoples urban lifestyle. Journal Of Consumer Culture, [S.L.], v. 1, n. 1, p. 1-19, 14 out. 2019. SAGE Publications. http://dx.doi.org/10.1177/1469540519882487.

MA, Y.; Kang, J.; Zhang, J.; Zheng, F. College Students' Consumption Behavior-A Case Study on Students in Ningxia University. Sustain, [S.L], v. 9, n. 4, Dev. 2019, 9, 576. NAO ACHEI

MALHEIROS, Clayton de Souza. Fato relevante: reabertura total de lojas. 2020. Disponível em: https://economia.estadao.com.br/fatos-relevantes/pdf/35297660.pdf Acesso em 13 nov. 2020

MEAH, Angela; JACKSON, Peter. Convenience as care: culinary antinomies in practice. Environment And Planning A: Economy and Space, [S.L.], v. 49, n. 9, p. 2065-2081, 28 jun. 2017. Disponível em: https://journals.sagepub.com/doi/10.1177/0308518X17717725. Acesso em: 13 nov. 2020. 
MITHIDIERI, Thiago. A evolução do e-commerce no Brasil. 2015. Disponível em: https://www.ecommercebrasil.com.br/artigos/a-evolucao-do-e-commerce-no-brasil/. Acesso em: 01 nov. 2020

MONTGOMERY, Cynthia A; PORTER, Michael. Estratégia: a busca da vantagem competitiva. Rio de Janeiro: Elsevier, 1998.

MOONEN, Frans. Os índios potiguara da Paraíba. $2^{a}$ ed. digital aumentada. Recife: 2008.

NEUMARK-SZTAINER, Dianne et al. Family meals and adolescents: what have we learned from Project EAT (Eating Among Teens). Public Health Nutrition, [S.L], v. 13, n. 7, p. 11131121, jul. 2010. Disponível: em: https://pubmed.ncbi.nlm.nih.gov/20144257/. Acesso em: 13 nov. 2020.

PITWAK, Ana Carolina; FERREIRA, Camila Lopes. A utilização do E-commerce como diferencial das organizações para a conquista de mercado. 2009. Disponível em: http://www.pg.cefetpr.br/incubadora/wp-content/themes/utfpr-gerec/artigos/14.pdf. Acesso: em 20 nov. 2020.

REEDY, Joel.; SCHULLO, Shauna. Marketing eletrônico: integrando recursos eletrônicos no processo de marketing. São Paulo: Cengage Learning, 2007.

RIO DE JANEIRO. Decreto no 46.973 de 16 de março de 2020. Reconhece a situação de emergência na saúde pública do Estado do Rio de Janeiro em razão do contágio e adota medidas de enfrentamento da propagação decorrente no novo coronavírus (COVID-19); e dá outras providências, Rio de Janeiro, 2020, pag.1. disponível em <https://pge.rj.gov.br/comum/code/MostrarArquivo.php?C=MTAyMjI\%2C > Acesso em 20 de nov. 2020.

RIO DE JANEIRO. Decreto no 47.285 de 23 de março de 2020. Determina a adpção de medidas adlcionais, pelo Município, para enfretamento do novo Coronavírus - COVID - 19, e dá outras providências. Rio de Janeiro, 2020, pag. 1-5. Disponível em <https://www.legisweb.com.br/legislacao/?id=392323> Acesso em 15 de out. de 2020.

ROGERS, David L. Transformação digital: repensando o seu negócio para a era digital. 1a. ed. São Paulo : Autêntica Business, 2017. Traduzido por Afonso Celso da Cunha Serra.

$\mathrm{ROH}$, Minjung; PARK, Kiwan. Adoption of $\mathrm{O} 2 \mathrm{O}$ food delivery services in South Korea: the moderating role of moral obligation in meal preparation. International Journal Of Information Management, [S.L.], v. 47, p. 262-273, ago. 2019. Disponível em: https://psycnet.apa.org/record/2019-34920-024. Acesso em: 13 nov. 2020.

SANTOS NETO, Artur Bispo dos. Capital e pandemia. Goiânia: Editora Phillos, 2020. Ebook.

SOUZA, Ailton Fernando de [et al.]. Análise financeira das demonstrações contábeis na prática. São Paulo : Trevisan Editora, 2015. Ebook.

TELLES, André. O futuro é smart: como as novas tecnologias estão redesenhando os negócios e o mundo em que vivemos. 1를 ed. Curitiba: PUCPRESS, 2018. 163 p. 
VOGEL, Denise. Das proto-cidades às smart cities: reflexão a partir do coronavírus. In: BORGES, Andrea; MARQUES, Leila (org.). Coronavírus e as cidades no Brasil: reflexões durante a pandemia. Rio de Janeiro: Outras Letras, 2020. p. 53-57.

WEARN, Rebecca. Does your dinner come from a dark kitchen?. 2019. Disponível em: https://www.bbc.com/news/business-47978759. Acesso em; 10 out. 2020.

YANASE, João. Custos e formação de preços: importante ferramenta para tomada de decisões. São Paulo: Trevisan Editora, 2018. Ebook.

BARDIN, Laurence. Análise de conteúdo. São Paulo: Edições 70, 2011, 229 Palavras-chave: Análise do conteúdo; Dados qualitativos; Análise de dados.

INSTITUTO QUALIBEST. CONSUMO DE COMIDA DELIVERY POR APLICATIVO. [2018]. Disponí vel em: www.institutoqualibest.com/wpcontent/uploads/2019/01/Infográfico_Delivery.pdf 
ANEXOS

Anexo 1 - Comunicado Burguer King

Anexo 2 - Roteiro das entrevistas 


\section{Comunicado Burger King}

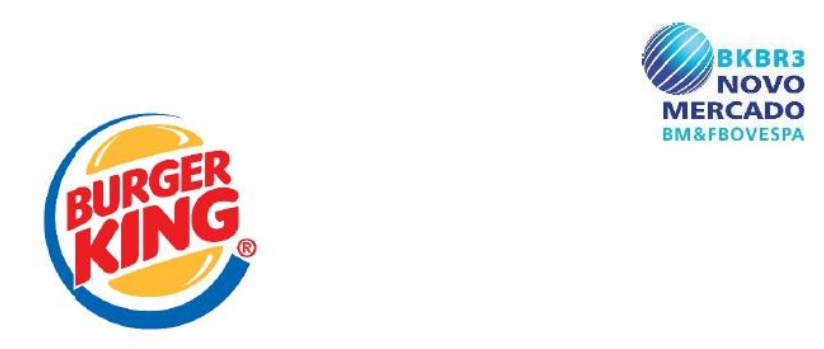

BK BRASIL OPERAÇÃO E ASSESSORIA A RESTAURANTES S.A.

CNPJ/MF n 13.574.594/0001-96

Companhia Aberta

\section{FATO RELEVANTE}

\section{Reabertura Total de Lojas}

O BK Brasil Operação e Assessoria a Restaurantes S.A. ("Companhia"), em observância ao disposto na Instrução da Comissão de Valores Mobiliários ("CVM") no 358/2002 e em complemento ao Comunicado ao Mercado divulgado pela Companhia em 20/03/2020 e ao Fato Relevante divulgado em 02/07/2020, comunica a seus acionistas e ao mercado em geral, que, nesta data, $100 \%$ dos nossos restaurantes, das marcas BURGER KING $^{\circledR}$ e POPEYES LOUISIANA KITCHEN®, já retornaram à operação. Ressaltamos, ainda, que a Companhia segue com 3 restaurantes em reforma e optou por não retomar as atividades de 19 operações, encerrando-as definitivamente no $3^{\circ}$ trimestre, como parte do seu plano de manutenção e otimização de portfólio.

Para reabertura das operações, seguimos atentamente todas as recomendações governamentais no que diz respeito às condições de funcionamento das lojas, tendo em vista o distanciamento social que junto das nossas já rigorosas medidas de higiene, protegem nossos clientes e colaboradores. Conforme previamente divulgado, dentre as ações implementadas para as aberturas, intensificamos os procedimentos de higienização dos nossos restaurantes, ampliamos o uso de equipamentos de proteção individuais, distribuímos máscaras para todos os nossos colaboradores, instalamos acrílicos de proteção nas lojas e enviamos termômetros para aferição de temperatura de colaboradores. A Companhia seguirá monitorando atentamente os desdobramentos da pandemia em nosso negócio.

Além da retomada de $100 \%$ das operações mencionada acima, a Companhia iniciou em 24/08/2020 as atividades da sua primeira operação "Ghost Kitchen" integrada das marcas BURGER KING ${ }^{\circledR}$ e POPEYES LOUISIANA KITCHEN® ${ }^{\circledR}$. Esse novo formato com foco exclusivo para a operação de Delivery tem o intuito de proporcionar a melhor experiência para os nossos clientes, com a máxima conveniência.

Barueri, 11 de setembro de 2020.

\section{Clayton de Souza Malheiros}

\section{Diretor de Relações com Investidores}


Anexo 2 - Roteiro das entrevistas

1) Qual seu nome?

2) Qual nome do negócio?

3) Qual bairro?

4) Tempo de funcionamento da empresa?

5) Número de colaboradores?

6) Tipo de cozinha?

7) Tipo de operação?

8) Qual foi o investimento inicial? Quais custos foram mais relevantes?

9) Como foi o processo de decisão de abertura da empresa?

10) Como a quarentena afetou as suas vendas?

11) Quais são os canais de venda?

12) Volume de pedidos por mês?

13) Ticket Médio (Por pedido)?

14) Vantagens das Dark Kitchens?

15) Desafios da modalidade de Dark Kitchen?

16) Como você vê o delivery quando a pandemia passar? 